\title{
Total regression of hepatocellular carcinoma bone metastases, after liver transplantation, with sorafenib-everolimus
}

\author{
Dimitrios Giakoustidis ${ }^{1}$, Athanasios Apostolos Gargavanis', Nikolaos Salveridis ${ }^{1}$, Evangelos Cholongitas ${ }^{2}$, \\ Emmanouil Sinakos ${ }^{2}$, Konstantinos Papapolychroniadis', Vassilios Papanikolaou ${ }^{1}$
}

${ }^{1}$ Division of Transplant Surgery, Department of Surgery, Medical School, Aristotle University of Thessaloniki, Hippokration General Hospital, 54642 Thessaloniki, Greece.

${ }^{2}$ The 4th Department of Internal Medicine, Medical School, Aristotle University of Thessaloniki, Hippokration General Hospital, 54642 Thessaloniki, Greece.

Correspondence to: Dr. Dimitrios Giakoustidis, Department of Surgery, Medical School, Aristotle University of Thessaloniki, 54642 Thessaloniki, Greece.E-mail: dgiak@auth.gr

How to cite this article: Giakoustidis D, Gargavanis AA, Salveridis N, Cholongitas E, Sinakos E, Papapolychroniadis K, Papanikolaou V. Total regression of hepatocellular carcinoma bone metastases, after liver transplantation, with sorafenib-everolimus. Hepatoma Res 2017;3:205-8.

Article history:

Received: 26 Jun 2017

Accepted: 29 Aug 2017

Published: 20 Sep 2017

\section{Key words:}

Liver transplantation,

hepatocellular carcinoma,

bone metastases,

sorafenib,

everolimus

\begin{abstract}
Hepatocellular carcinoma (HCC) represents the 5th commonest malignancy worldwide. Liver transplantation consist a radical and most efficient treatment for HCC. Tumor recurrence or metastases after liver transplantation is not uncommon. Hereby is presented a case of a patient transplanted for alcoholic liver disease and HCC and presented with bone metastases a few months later. Treatment with sorafenib and everolimus showed full regression of the metastases. In conclusion, the point of this report is to advertise a single case of total regression of bone lesions due to HCC recurrence, with the combination of mammalian target of rapamycin and sorafenib, along with radiation.
\end{abstract}

\section{INTRODUCTION}

Hepatocellular carcinoma (HCC) consists a healthcare problem with rising incidence rates..$^{[1]}$ Liver transplantation (LT) is a radical treatment for HCC. In order a patient with $\mathrm{HCC}$ to receive a liver graft, he must fulfill certain enlisting criteria ${ }^{[2]}$ and no extrahepatic disease. Tumor recurrence or metastases after liver transplantation for HCC is not uncommon. Sorafenib has been used as rescue therapy in patients with recurrent HCC after $\mathrm{LT}^{\left[{ }^{[3]}\right.}$ We hereby present a case of a patient transplanted for alcoholic liver disease (ALD) and $\mathrm{HCC}$ that presented with bone metastases a few months later. He was treated with sorafenib and everolimus, showed full regression of the metastases and he is still alive 9 years after LT.

\section{CASE REPORT}

A 63-year-old male patient was enlisted for LT for 
liver cirrhosis due to ALD. He was presenting portal hypertension, ascites and episodes of encephalopathy. His model for end-stage liver disease (MELD) score was 21 . He was transplanted with piggy-back technique, from a heart-beating donor. Cold ischemia time was $9 \mathrm{~h}$. He was put on triple immunosuppression maintenance therapy with prednizolone, mycophenate mofetil and cyclosporine.

The explant's pathology report revealed the presence of two incidental HCC lesions measuring 15 and $20 \mathrm{~mm}$, with no portal involvement, of medium differentiation, with pseudocapsule, clear-cell type, withoutextrahepatic nodules or other findings. The post-operative course was uneventful. His immunosuppression therapy was changed to tacrolimus and everolimus, along with tapering of prednizolone. Tacrolimus and everolimus levels were monitored.

Two months post transplantation the patient complained of back pain. Bone Scanning 99m Technetium helix destabilizing protein (99mTc-HDP) revealed 2 osteoblastic lesions on the T8 and T11, possibly secondary-HCC lesions. Prednizolone was ceased and sorafenib $400 \mathrm{mg}$ bid was initiated, along with ibandronic acid (diphosphonic acid) qd. Radiotherapy was induced, photons $60 \mathrm{Co}$. He received a total of 2,300 centigray (cGy), in doses of $46 \mathrm{cGy}, 5$ times/week.

Otherwise the patient was in good condition. His kidney function with radioisotope renography with $99 \mathrm{~m}$ Technetium diethylene triamine pentoacetic acid (99mTc-DTPA) was $52 \mathrm{~mL} / \mathrm{min} / 1.73 \mathrm{~m}^{2}$. Alpha fetoprotein (AFP) level was $6.6 \mathrm{ng} / \mathrm{mL}$.

Seven months after the first discovery of the spinal osteoblastic lesions, the repetition of the $99 \mathrm{mTc}-\mathrm{HDP}$, revealed further progress of the disease [Figure 1]. New lesions were being detected at the 5th, 6th, 7th, and 8th left ribs. Magnetic resonance imaging (MRI) scan failed to reveal any additional findings. Therapy remained the same.

Another 99mTc-HDP bone scanning 18 months post LT showed, for the first time, regression of the rib lesions, while the known 2 spinal lesions were significantly minimized. Therapy remained unaltered. Patient's clinical condition was excellent.

Finally, 28 months post $\mathrm{LT}$, a new bone scanning certified the complete regression of all the osteolytic lesions [Figure 2].

\section{DISCUSSION}

$\mathrm{HCC}$ is the third cause of cancer related mortality nowadays, according to World Health Organization (WHO). The primary etiologic factor is liver cirrhosis. To the present case, HCC was incidental finding in the explant. A prior transplantation computed tomography (CT) failed to detect the presence of liver or extrahepatic lesions. Additionally, AFP levels were low [Table 1], failing to justify a position emission tomography (PET) scan preoperatively. Even if the patient was evaluated for Milan Criteria (MC), according to the explants' pathology, the patient would be inside MC. Moreover, piggy-back technique is the standard LT procedure performed by our center, like many other centers universally. It does not consisting a risk factor for HCC recurrence, compared to the classic technique.

The induction of sorafenib, an oral multi-kinase inhibitor, targeting $\mathrm{HCC}$ control, demands compensated liver function, and applies to patients with advanced HCC. ${ }^{[4]}$ Regarding HCC recurrence post LT, the current strategy remains controversial. Recurrence can be

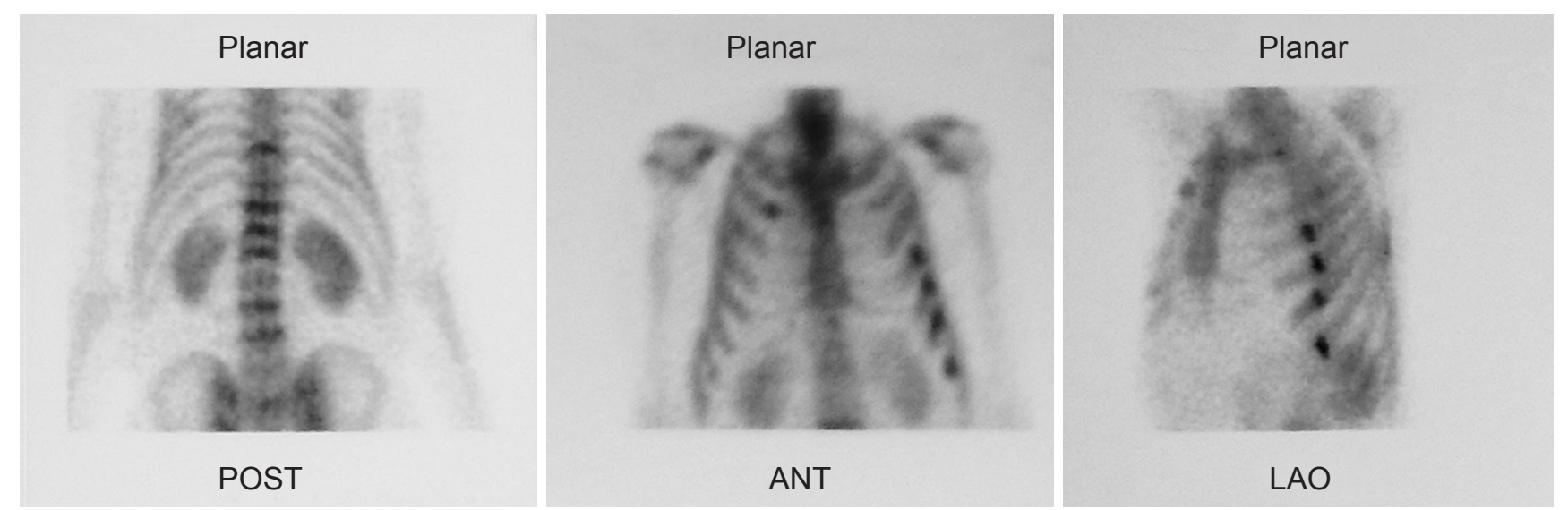

Figure 1: Initial 99m Technetium helix destabilizing protein scintigraphy showing metastatic lesions in the spine and ribs. POST: posterior; ANT: anterior; LAO: left anterior oblique 


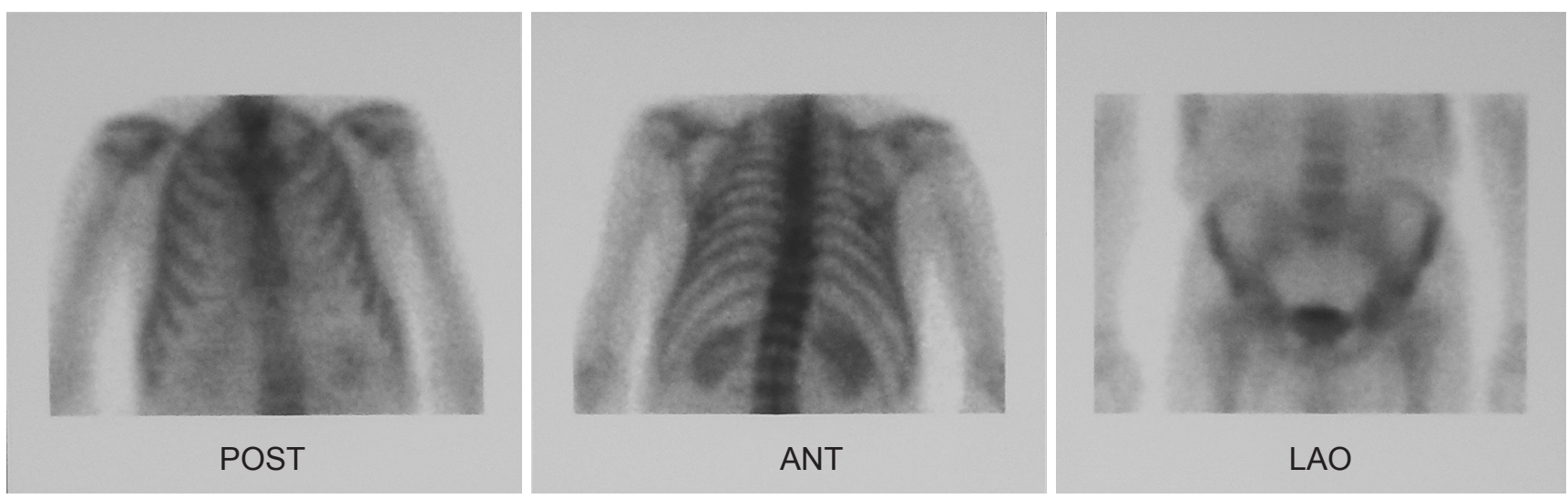

Figure 2: 99m Technetium helix destabilizing protein scintigraphy post sorafenib, immunosuppresion modification and radiation, showing regression of metastatic lesions in the spine and ribs. POST: posterior; ANT: anterior; LAO: left anterior oblique

located to liver graft, lung, bone, abdominal lymph nodes, adrenal glands and peritoneum. According to De Angelis et al., ${ }^{[5]}$ on a total of 61 studies selected, the median time recurrence presented was 13 months post transplantation, while $67 \%$ of patients presented with extra-hepatic lesions. ${ }^{[5]}$ Overall survival was 12.97 months.

A classification of management according to the location of the recurrence has been attempted, recently. Toso et al. ${ }^{[6]}$ when HCC reappear, underline the importance of immunosuppresion change to mTOR and propose initiation of sorafenib only for nonresectable multiple lesions, or cases that cannot profit of less invasive strategies, like radio frequency ablation or transarterial chemo embolization. If the recurrence is limited in the liver, without extrahepatic spread, local excision should be attempted. ${ }^{[7]}$ The initiation of sorafenib finds place in cases of advanced HCC, when no other approach is plausible.

Table 1: Patient data, before and after liver transplantation

\begin{tabular}{lcc}
\hline Characteristics & Preoperative & $\begin{array}{c}\text { 30 days post-liver } \\
\text { transplantation }\end{array}$ \\
\hline MELD score & 21 & - \\
Child-Pough stage & C (10 points) & - \\
AFP $(\mathrm{ng} / \mathrm{mL})$ & 2.8 & 5.2 \\
CA $19-9(\mathrm{ng} / \mathrm{mL})$ & 25.47 & 5.2 \\
CEA $(\mathrm{ng} / \mathrm{mL})$ & 3.46 & 1.58 \\
PLT $(\mathrm{K} / \mathrm{hL})$ & 66,000 & 109,000 \\
INR & 1.96 & 0.89 \\
AST $(\mathrm{U} / \mathrm{L})$ & 36 & 22 \\
ALT $(\mathrm{U} / \mathrm{L})$ & 20 & 29 \\
ALP $(\mathrm{U} / \mathrm{L})$ & 88 & 64 \\
BIL $(\mathrm{mg} / \mathrm{dL})$, total/direct & $7.0 / 3.3$ & $1.0 / 0.23$ \\
$\gamma \mathrm{GT}(\mathrm{U} / \mathrm{L})$ & 20 & 46 \\
\hline
\end{tabular}

MELD: model for end-stage liver disease; AFP: alpha fetoprotein; CA: carbohydrate antigen; CEA: carcinoembryonic antigen; PLT: platelets; INR: international normalized ratio; AST: aspartate transaminase; ALT: alanine aminotransferase; ALP: alkaline phosphatase; BIL: bilirubin; GT: glutamyl transpeptidase
This plan though, is not free of complications. Discontinuation of the sorafenib treatment due to adverse side effects is not uncommon. ${ }^{[8]}$ The induction of radiation as an only and palliative treatment, is not improving the survival rates. In the study of Seong et al., ${ }^{\left[{ }^{[0]}\right.} 51$ patients received radiation therapy for 77 osteolytic metastatic lesions. Though there was pain relief in 56 lesions (73\%), 1 -year survival was only $15 \%$. In the review of He et al., ${ }^{[10]}$ radiation therapy for bone lesions, due to HCC post LT, improves patients' quality of life. It has the same impact for transplanted patients, as in non-transplanted.

Vanishing of osteolytic lesions, to a patient under treatment with sorafenib-mToR, after radiation, has not been reported so far, to our knowledge. Though no biopsy was being done, we are convinced on the malignancy: the pain and imaging spread was distinctive, and they disappeared after treated like bone recurrence.

The patient had an interesting natural history of the disease. HCC was an incidental finding of explants' pathology. Metastasis to the bones was an unexpected event, since tumors were small and AFP was low. Nevertheless the patient presented with spine and later with ribs metastases. Oncologically he was treated primary with sorafenib and secondary with mTOR drug inhibitor everolimus, along with radiation. His immunosuppression therapy was revised accordingly.

Our patient discontinued sorafenib 4 years ago, due to coronary disease. He remains under mTOR treatement, without new HCC recurrence [Figure 3].

\section{DECLARATIONS}

\section{Authors' contributions}

Concept: D. Giakoustidis, V. Papanikolaou 


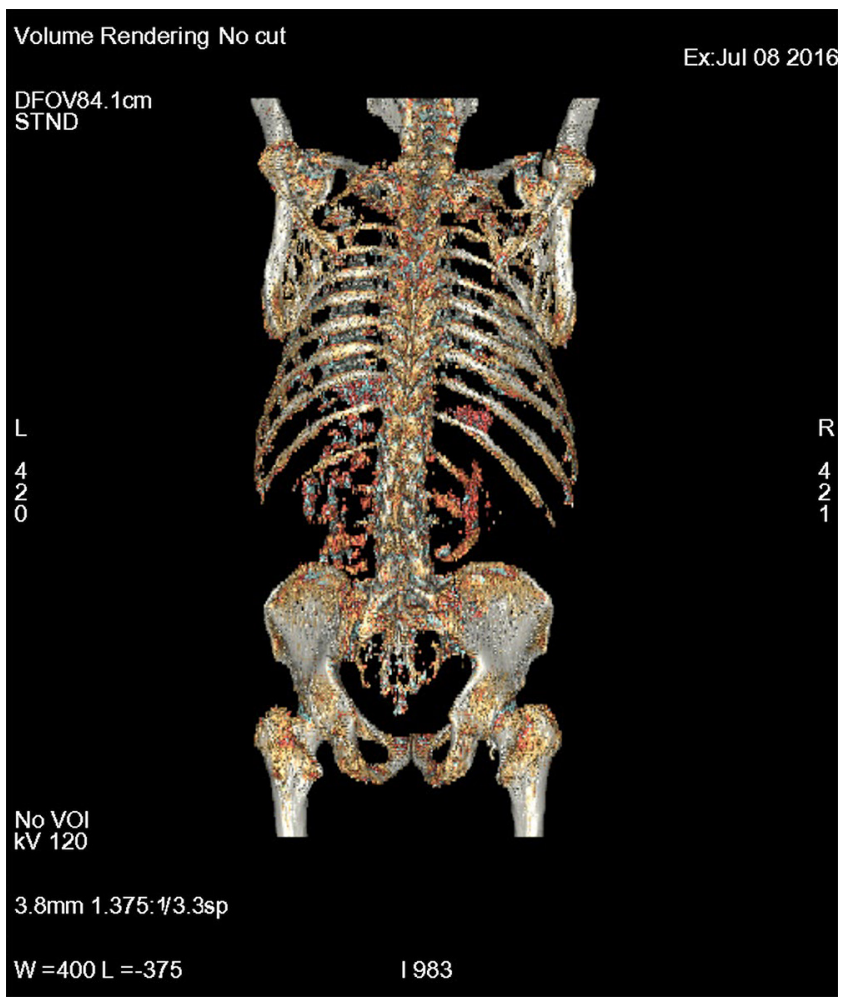

Figure 3: Recent 18-FDG-PET/CT (Volume rendering) showing no lesions in ribs or spine. FDG: fluorodeoxyglucose; PET: position emission tomography; CT: computed tomography

Literature search: D. Giakoustidis, A.A. Gargavanis, N. Salveridis, E. Cholongitas, E. Sinakos, K. Papapolychroniadis, V. Papanikolaou

Data acquisition: D. Giakoustidis, A.A. Gargavanis, N. Salveridis, E. Cholongitas, E. Sinakos

Data interpretation: D. Giakoustidis, A.A. Gargavanis, N. Salveridis, E. Cholongitas, E. Sinakos, K. Papapolychroniadis, V. Papanikolaou

Manuscript preparation: D. Giakoustidis, A.A. Gargavanis, N. Salveridis, E. Cholongitas, E. Sinakos Manuscript editing: D. Giakoustidis

Manuscript review: K. Papapolychroniadis, V. Papanikolaou

\section{Financial support and sponsorship None.}

\section{Conflicts of interest}

There are no conflicts of interest.

\section{Patient consent}

The patient has provided us an informed written consent, available upon request.

\section{Ethics approval}

An ethics approval is not necessary for a case report; the informed written consent is sufficient.

\section{REFERENCES}

1. El-Serag HB, Davila JA, Petersen NJ, McGlynn KA. The continuing increase in the incidence of hepatocellular carcinoma in the United States: an update. Ann Intern Med 2003;139:817-23.

2. Mazzaferro V, Regalia E, Doci R, Andreola S, Pulvirenti A, Bozzetti F, Montalto F, Ammatuna M, Morabito A, Gennari L. Liver transplantation for the treatment of small hepatocellular carcinomas in patients with cirrhosis. N Engl J Med 1996;334:693-9.

3. European Association for Study of Liver; European Organisation for Research and Treatment of Cancer. EASL-EORTC clinical practice guidelines: management of hepatocellular carcinoma. Eur J Cancer 2012;48:599-641.

4. Llovet JM, Ricci S, Mazzaferro V, Hilgard P, Gane E, Blanc JF, de Oliveira AC, Santoro A, Raoul JL, Forner A, Schwartz M, Porta C, Zeuzem S, Bolondi L, Greten TF, Galle PR, Seitz JF, Borbath I, Häussinger D, Giannaris T, Shan M, Moscovici M, Voliotis D, Bruix J; SHARP Investigators Study Group. Sorafenib in advanced hepatocellular carcinoma. N Engl J Med 2008;359:378-90.

5. De'Angelis N, Landi F, Carra MC, Azoulay D. Managements of recurrent hepatocellular carcinoma after liver transplantation: a systematic review. World J Gastroenterol 2015;21:11185-98.

6. Toso C, Mentha G, Majno P. Integrating sorafenib into an algorithm for the management of post-transplant hepatocellular carcinoma recurrence. J Hepatol 2013;59:3-5.

7. Mazzola A, Costantino A, Petta S, Bartolotta TV, Raineri M, Sacco R, Brancatelli G, Cammà C, Cabibbo G. Recurrence of hepatocellular carcinoma after liver transplantation: an update. Future Oncol 2015;11:2923-36

8. Zavaglia C, Airoldi A, Mancuso A, Vangeli M, Viganò R, Cordone G, Gentiluomo M, Belli LS. Adverse events affect sorafenib efficacy in patients with recurrent hepatocellular carcinoma after liver transplantation: experience at a single center and review of the literature. Eur J Gastroenterol Hepatol 2013;25:180-6.

9. Seong J, Koom WS, Park HC. Radiotherapy for painful bone metastases from hepatocellular carcinoma. Liver Int 2005;25:261-5.

10. He J, Zeng ZC, Fan J, Zhou J, Sun J, Chen B, Yang P, Wang BL, Zhang BH, Zhang JY. Clinical features and prognostic factors in patients with bone metastases from hepatocellular carcinoma after liver transplantation. BMC Cancer 2011;11:492. 